\title{
The Transformation from Traditional Nonprofit Organizations to Social Enterprises: An Institutional Entrepreneurship Perspective
}

\author{
Wai Wai Ko ${ }^{1} \cdot$ Gordon Liư ${ }^{2}$
}

Received: 16 January 2019 / Accepted: 24 January 2020 / Published online: 30 January 2020

(c) The Author(s) 2020

\begin{abstract}
The development of commercial revenue streams allows traditional nonprofit organizations to increase financial certainty in response to the reduction of traditional funding sources and increased competition. In order to capture commercial revenuegenerating opportunities, traditional nonprofit organizations need to deliberately transform themselves into social enterprises. Through the theoretical lens of institutional entrepreneurship, we explore the institutional work that supports this transformation by analyzing field interviews with 64 institutional entrepreneurs from UK-based social enterprises. We find that the route to incorporate commercial processes and convert traditional nonprofit organizations into social enterprises requires six distinct kinds of institutional work at three different domains; these are- "engaging commercial revenue strategies", "creating a professionalized organizational form", and "legitimating a socio-commercial business model". In elaborating on social entrepreneurship research and practice, we offer a comprehensive framework delineating the key practices contributing to the transformation from traditional nonprofit organizations to social enterprises. This extends our understanding of the ex-ante strategy of incorporating commercial processes within social organizations. Furthermore, the identification of these practices also offers an important tool for scholars in this field to examine the connection (or disconnection) of each practice with different ethical concerns of social entrepreneurship in greater depth.
\end{abstract}

Keywords Institutional entrepreneurship $\cdot$ Institutional logic $\cdot$ Transformation $\cdot$ Nonprofit organization $\cdot$ Social entrepreneurship

\section{Introduction}

Traditional nonprofit organizations (NPOs) are being affected by the reduction of private donations and government funding, and are facing an increasingly competitive business environment in the modern era (Dart 2004; Liu et al. 2015; Toepler 2006). For example, the National Council for Voluntary Organizations estimates that joint revenue from central government and local authorities to UK charities fell by at least $£ 2.8$ billion in real terms between 2010/2011 and 2015/2016 (Laforest 2013). More than

Gordon Liu

gordon.liu@open.ac.uk; cygliu@gmail.com

Wai Wai Ko

joyce.ko@brunel.ac.uk

1 Brunel Business School, Brunel University, Uxbridge UB8 3PH, UK

2 The Open University Business School, The Open University, Milton Keynes MK7 6AA, UK
168,000 social organizations were registered in English and Wales in 2017, the highest level in almost a decade (Hillier 2018). In response to these challenges, scholars suggest that traditional NPOs can acquire commercial revenue streams to ensure financial self-sufficiency (e.g., Bush 1992; Maier et al. 2016; Pache and Santos 2013).

To effectively implement practices that attract commercial revenue streams, traditional NPOs need to deliberately reconfigure their current operating models and introduce new business functions (Fitzgerald and Shepherd 2018; Hwang and Powell 2009). Subsequently, a new form of NPO that is more entrepreneurial, market-oriented, and businesslike often emerges from these complex activities (Dart 2004; Maier et al. 2016). Scholars describe this new form of NPO as "social enterprises (SEs)" (Fitzgerald and Shepherd 2018; Liu et al. 2015). From the perspective of organizational goals, SEs focus on creating social value, which is in line with our interpretation of NPOs being social mission-driven organizations (Bull and Ridley-Duff 2019; Weerawardena and Mort 2012). However, unlike NPOs that traditionally 
rely on private donations and government funding, SEs focus on generating incomes from commercial activities (Defourny and Nyssens 2017; Litrico and Besharov 2019). Thus, we define a SE as a form of NPO that makes use of productive activities to generate commercial revenue in support of its social mission. This definition is in line with the Earned Income School of thought ${ }^{1}$ (on SEs) that stresses the vital role of SEs in organizing a range of commercial practices to help diversify their funding base and manage the risks associated with income generation (Bacq and Janssen 2011; Defourny and Nyssens 2012). We argue that this practice of turning traditional NPOs into SEs fits the description of institutional entrepreneurship. Institutional entrepreneurship represents activities of transforming established institutions in ways that diverge from the status quo (Maguire et al. 2004; Rao and Singh 2001). From this perspective, the SEs' executives (high-ranking managers: CEO, Chief Operation Officer, Financial Director, etc.) play the role of "institutional entrepreneurs" who engage in activities (incorporating commercial processes within social organizations) to transform existing institutions (i.e., traditional NPOs) into new ones (i.e., SEs) (Desa 2012; Tracey et al. 2011).

Previous studies that investigate the formation of SEs (transforming from traditional NPOs) often focus on understanding how institutional entrepreneurs respond to and accommodate dual social and commercial processes (e.g., Battilana et al. 2015; Cooney 2006; Wry and York 2017). For example, Pache and Santos (2013) advance the manipulation of the templates provided by the multiple logics to gain acceptance of SEs. Bruneel et al. (2016) recommend paying attention to the governance of the tension between competing demands inside as well as outside the organizations. Fitzgerald and Shepherd (2018) suggest four different ways-integration, compartmentalization, aggregation, and subordination - to manage dual commercial and social foci. Although this research line has generated valuable theoretical insights, one area which remains relatively unexplored (with a few notable exceptions such as Desa 2012; Tracey et al. 2011) is how SEs are transformed from traditional NPOs by incorporating commercial processes within social

\footnotetext{
1 We want to acknowledge that there are three major schools of thought on SEs (Bacq and Janssen 2011; Defourny and Nyssens 2012). Other than the Earned Income School of thought, the Social Innovation School of thought considers social enterprises as changemakers that focus on finding innovative ways to solve social problems (Dees and Anderson 2006). The EMES (Emergence des Enterprises Sociales en Europe) School of thought indicates that social enterprises should directly involve themselves in building and providing social products and services to benefit the community (Defourny and Nyssens 2012). Our study focusses on understanding the transformation of NPOs to SEs to ensure financial self-sufficiency. Therefore, we prefer the Earned Income School of thought and adopt its definition of SEs.
}

organizations in the first place. To answer this question, we conduct and analyze 64 field interviews held with institutional entrepreneurs of UK-based SEs who have participated in the process of transforming traditional NPOs into SEs.

Specifically, we find that the transformation processes begin by traditional NPOs engaging the commercial revenue strategy. Through building commercial revenue-generating mechanisms and establishing business partnerships with for-profit organizations, traditional NPOs are able to exploit commercial opportunities and develop commercial revenue streams. Next, we find that the transformation processes lead to the creation of a professionalized organizational form to respond to the changing environment. In particular, institutional entrepreneurs focus their attention on constructing business-like working processes and supporting structures within traditional NPOs, and developing capacity for managing business-like operations. Finally, we find that the transformation processes place great emphasis on legitimating the socio-commercial business model by advocating business-oriented strategic direction and maintaining social organization status to address stakeholders' concerns about the newly emerged SEs.

In developing our argument, we make four contributions. First, through the theoretical lens of institutional entrepreneurship, we identify different domains of institutional work that support the incorporation of commercial practices within traditional NPOs. Our work sheds new light on how institutional entrepreneurs take on an active role in transforming traditional NPOs into SEs. Second, we extend the current literature on the formation of SEs through the transforming of traditional NPOs; such literature primarily focusses on the "ex-post" strategy of managing tensions from dual social and commercial processes (e.g., Battilana et al. 2015; Fitzgerald and Shepherd 2018; Pache and Santos 2013; Wry and York 2017) rather than on the "ex-ante" strategy of incorporating commercial processes within social organizations (e.g., Desa 2012; Tracey et al. 2011). This contribution is important because a critical determinant of the likelihood that such organizations will survive environmental jolts is whether the traditional NPO can convert to a SE (Liu and Ko 2014; Toepler 2006). As many traditional NPOs struggle to be self-sufficient, this transformation practice becomes an important topic for practitioners and academics. Third, the previous research in this topic shows over-reliance on a single case or small numbers of case studies (e.g., Fitzgerald and Shepherd 2018; Pache and Santos 2013; Vickers et al. 2017). This limits the conclusions that one can draw across different SE sectors. Our research incorporates institutional entrepreneurs' experience from multiple SE sectors to provide a more generalized picture of the transformation from traditional NPO to SE. Finally, our work adds to the business ethics perspective of social entrepreneurship in the discussion of "impure" motives in 
pursuing social missions (e.g., Bacq et al. 2016; Bull and Ridley-Duff 2019; Chell et al. 2016). Our finding of specific individual practices in supporting the incorporation of commercial processes provides a tool for scholars in this field to examine the ethical concerns for each practice and to ask more specific ethical questions about the transformation from traditional NPOs to SEs.

\section{Institutional Entrepreneurship Perspective of Organizational Transformation}

From the perspective of institutional theorists, an organization is a form of institution (Greenwood et al. 2010; Mutch 2018). The institutional arrangements (e.g., policies, systems, and operational processes) set up by the organization are potent forces to direct its staff to engage in a specific pattern of actions (e.g., improve operational efficiency). The concept of institutional entrepreneurship describes the deliberate act of transforming the existing institutional arrangements to new ones (Greenwood et al. 2010; Maguire et al. 2004). This organizational transformation process usually involves the installation of new institutional arrangements within the existing organization. As a result, a newly emerged organization from this transformation comprises different belief systems (i.e., values), operational foci, and organizing frameworks that its staff use to assign meaning to and organize their tasks (Garud et al. 2002; Rao and Singh 2001).

Some notable examples include Garud et al. (2002) study of how Sun Microsystem (American software developer acquired in 2010 by Oracle Corporation-an American technology company) adopted an open-system strategy ${ }^{2}$ and transformed itself from the company that licenses its software to computer manufacturers to a technology sponsor. Lawrence and Phillips (2004) investigate how whale-watchers on Canada's west coast pursued business opportunities in the changing macro-cultural environment (i.e., anti-whaling) and engaged in tourism operations to transform themselves from fun-oriented, educational wildlife tour providers to a commercial whale-watching company. Munir and Phillips (2005) study how Kodak (Eastman Kodak CompanyAmerican technology company) introduced new technology (i.e., roll-film camera) and practices (i.e., advertising) to transform itself from the professional photography practices equipment provider to the company that promotes photography as an integral part of social life. Zietsma and Lawrence (2010) explore the processes of introducing and

\footnotetext{
${ }^{2}$ Open-system strategy places part of Sun Microsystem's private knowledge in the public domain (i.e., download and use the software for free) and allows both rivals and vendors of complementary products easy access to the company's proprietary technology-Java (Garud et al. 2002).
}

implementing ecosystem-based management practices by a forest company in British Columbia, Canada to transform the organization into a more environmentally sustainable entity, while Gawer and Phillips (2013) investigate the processes by which Intel Corporation (an American technology company) shifted from a traditional supply chain logic to the adoption of platform logic in managing its business partnerships and transformed itself into a platform leader. Dalpiaz et al. (2016) study how Alessi (an Italian manufacturer of household goods) combined the logic of industrial manufacturing and cultural production, and transformed itself into a company that introduces products with an innovative artistic design to the market.

Following a close examination of these studies, we detect that the engagement of organizational transformation through the lens of institutional entrepreneurship usually coincides with the introduction of new practices (e.g., developing new products or services, etc.) and the emergence of the new organizational form (e.g., organizational structures and operating procedures) (Maguire et al. 2004; Phillips and Tracey 2007). More specifically, to realize new business opportunities, organizations often need to develop and present new practices. Such actions usually involve the engagement of organizational transformation because the current organizational forms-a distinctive combination of organizational structures and operating procedures ${ }^{3}-$ prevent organizations from effectively exploiting new business opportunities. Through building new organizational structures and operating procedures, organizations are better positioned to respond to the changes in the business environment (Greenwood and Suddaby 2006; Hwang and Powell 2009; Palacios et al. 2016). For example, Greenwood and Suddaby (2006) find that the "Big Five" accounting firms ${ }^{4}$ transformed their organizational forms from collegial control

\footnotetext{
${ }^{3}$ Given its wide acknowledgment, there has no agreement on how organizational form should be defined (Greenwood and Suddaby 2006; Lewin et al. 1999). For example, Ingram (1996, p. 85) defines an organizational form as "the combination of an organizational structure and an organizational strategy". Rao and Singh (2001, p. 244) describe an organizational form as "novel recombinations of core organizational features involving goals, and authority relations". Others such as Greenwood and Suddaby (2006) and Tracey et al. (2011) refer to an organizational form as a distinctive "configuration of structures and practices". Despite these differences, scholars generally agree that an organizational form is manifestations of institutional arrangements adopted by an organization, which reflect in its unique organizational structures and operating procedures (Huybrechts and Haugh 2018; Palacios et al. 2016; Rao et al. 2000). We, therefore, describe organizational form as an organization's distinctive combination of organizational structure and operating procedures in our study.

4 The five largest accounting firms-Arthur Andersen, Deloitte Touche Tohmatsu, Ernst \&Young, KPMG, and PricewaterhouseCoopers-are known as the "Big Five" (Greenwood and Suddaby 2006)
} 
(committees) to specialized "full-time" management style when they introduced multidisciplinary practices (the combination of accounting, legal advice, and management consulting services). These revised organizational forms allow the Big Five accounting firms to cross-sell a diversified range of services effectively.

Previous studies on organizational transformation from the perspective of institutional entrepreneurship also place great emphasis on legitimation (Greenwood and Suddaby 2006; Maguire et al. 2004). Legitimacy refers to the "perceived appropriateness of an organization to a social system in terms of rules, values, norms, and definitions" (Deephouse et al. 2017, p. 32) by organizations' stakeholders. An important aspect of organizational transformation is to find ways to establish legitimacy by addressing stakeholders' concerns about institutional changes. Without the establishment of legitimacy, the new practices, and new organizational forms that emerge from such transformation, will struggle to access resources from stakeholders (Bolzani et al. 2019; Hardy and Maguire 2017; Zietsma and Lawrence 2010). For example, Maguire et al. (2004) find that the establishment of wide legitimacy by bridging diverse stakeholders (HIV/AIDS community, and treatment advocates, pharmaceutical companies) has allowed Canadian Treatment Advocates Council (CTAC - a new organizational form) and its treatment consultation and information exchange services (new practices) to continue to access resources from these stakeholders.

In summary, the institutional entrepreneurship perspective of organizational transformation highlights (1) the introduction of new practices to exploit fresh opportunities, (2) the development of new organizational structures and operating procedures (i.e., organizational form) to respond to the changing environment, and (3) the establishment of legitimacy to address stakeholders' concerns about institutional change. To the best of our knowledge, no studies to date have explored all three aspects of action in a single study to provide a more comprehensive view on how traditional NPOs incorporate commercial processes into their existing operations and transform themselves into SEs. Our research, therefore, extends a small but important body of work that adopted institutional entrepreneurship as the theoretical lens to study the formation of SEs (e.g., Desa 2012; Tracey et al. 2011). We explore the kinds of institutional work required to support the transformation from traditional NPOs to SEs. We now turn to a description of our research method.

\section{Research Method}

\section{Research Context and Data Sources}

Our research context is UK-based SEs. In the face of spending cuts, the UK government is increasingly championing traditional NPOs to invest in the local community and deliver aspects of public service in ways that enhance their social impact on the community (HM Treasury 2002; NVCO 2012). During recent decades, demographic and social changes continued to expand the need for social services, leading to an increase in the number of new entrants, which has intensified the competition for funding and other resources among traditional NPOs. Thus, the most timely and important challenge that traditional NPOs face in the UK is to find ways to improve their self-sufficiency. In order to address this challenge, many UK-based traditional NPOs incorporate commercial processes within their business model and transform themselves into SEs (Ko and Liu 2015; Liu et al. 2015). UK-based SEs, therefore, present a context for us to study the transformation from traditional NPOs to SEs.

We gathered interview data from institutional entrepreneurs (high-ranking managers: CEO, Chief Operation Officer, Financial Director, etc.) of UK-based SEs. As discussed above, we define SEs as NPOs that make use of productive activities to generate commercial revenue in support of their social missions. Based on this definition, we identified SEs as organizations that have generated commercial revenue and registered as social organizations. We compiled our sample list of organizations from the Charity Communication UK website and randomly selected registered charities that generate a portion of their revenue from commercial (i.e., trading activities) sources (Charity Commission UK 2016). We sent out 300 invitation letters to the CEOs of these organizations. In the end, we conducted 64 interviews (one interview per organization), representing a response rate of roughly $21 \% .^{5}$ Among them, 39 CEOs agreed to participate in our interviews, while the remaining 25 CEOs directed our interview requests to other executives/ senior managers (such as Chief Operation Officer, Financial Director, Commercial Director) of SEs, whom they believed were more knowledgeable about the issues regarding the incorporation of commercial processes within their

\footnotetext{
5 We want to note that 27 CEOs wrote back saying that they did not wish to participate in our study, because they did not consider their organizations as SEs. Upon receiving their responses, we immediately wrote back to suggest that the revenue model of their organization (generates a portion of their revenue from commercial sources) fit our definition of SEs. Unfortunately, none of them agreed to participate in our study. We reason that whether NPOs with commercial processes are SEs is very much "in the eye of the beholder" (despite the definition that we use in this study) and the transformation into one is inherently subjective. Furthermore, this is also possibly the case among 209 CEOs who did not respond to our interview invitation. Some of them also did not agree with our definition of SEs. However, we have no way to tell the exact numbers of CEOs. In general, this disagreement about "what SE is" reflects various "popular" definitions of SEs used by academics and practitioners in relevant fields as mentioned in previous notes.
} 
organizations. Table 1 in Appendix provides a breakdown of the SEs' sectors and the job functions of interviewees. The average annual revenue of these SEs is $£ 4,180,478$, of which (on average) roughly $67 \%$ of revenue is generated from nonvoluntary ${ }^{6}$ sources. These SEs employed full-time staff ranging from 5 to 434 people. Each interview lasted between 25 and 85 min (average of 56 min each).

To guide the semi-structured interviews, we developed a standard interview protocol. We tested our interview protocol with three CEOs and one SE Fundraising Manager (not included in our final sample) who agreed to participate in our pilot study and provided some important feedback based on which we refined our interview protocol. During the actual interview, we began with a brief description of the background of the research project and explained the key terms (such as traditional NPOs, SEs, business-like, etc.) that we were to use in the interview questions. Each interviewee was generally asked to address the following four issues based on their experience of the transformation from traditional NPO to SE.

- What are your organizations' funding sources and your organization's approaches to ensure their sustainability?

- How does an organization like yours transform itself to become a more market-oriented, business-like social enterprise? What are some of the approaches that separate your organization from better-/poorer-performing organizations in terms of transformation?

- How do you, as top manager (and other top managers), initiate and manage the transformation of your organization? How is this process/practice carried out?

- What are the challenges faced by you (and other top managers) regarding transformation, and what are your approaches to handle these challenges?

Based on the responses, we probed deeper with additional questions to elicit other insights. We encouraged the interviewees to provide concrete examples to support their commentary. We discussed examples that they experienced during the transformation and their reflections on these. In addition, when an interviewee recounted a specific event, we made it a point to discuss that event with them after they had responded to our structured questions. These discussions helped us refine our understanding of the data. To triangulate

\footnotetext{
${ }^{6}$ The voluntary sources of income include gifts, donations and legacies from the public and grants from government and other charitable foundations, from which nonvoluntary sources of income include income from trading (e.g., providing goods and services to the public), investment (e.g., dividends, interest and rents), and charitable activities (e.g., fees or grants specifically for goods and services supplied by the charity to meet the needs of its beneficiaries) (Charity Commission UK, 2016).
}

the interview data, we also obtained documents (i.e., annual report) and information (i.e., facts) from SEs' websites or other public sources (i.e., newspaper).

\section{Data Analysis}

As we collected interview data, we also began to analyze them. We employed NVivo 10 qualitative research software to assist with our data analysis and followed the grounded theory-building approach (Strauss and Corbin 2008). Such an analytical approach allows researchers to impose qualitative rigor in demonstrating the connections among data, the emerging concepts, and the resulting grounded theory (Gioia et al. 2013; Goulding 2002). This is particularly useful for building new theories or elaborating on existing theories. In this research, we consider grounded theory is the most appropriate approach to investigate the incorporation of commercial processes within traditional NPOs because such practice is notably under-examined from the institutional entrepreneurship perspective of organizational transformation.

We followed the suggestions from Gioia et al. (2013) to conduct our data analysis. More specifically, in the initial phase of grounded theory, we tried to identify many concepts (codes) and made little attempt to categorize them to begin with. In the next step, we sought similarities and differences among these concepts to connect ideas (i.e., theories) and research questions. This allowed us to develop several second-order themes which provided meaning and focus to each theme. Once a workable set of themes was in hand, we assembled them into aggregate theoretical dimensions. In practice, we first "coded" each interview transcript separately on the basis of in vivo terms, phrases or descriptions used by the interviewees, which all revolved around the individual practices that related to the incorporation of commercial processes within social organizations (concepts). Next, we started discerning linkages among the concepts that could be collapsed into theoretically distinct clusters of institutional work. For example, comments relating to the work of "introducing new profit-seeking business practices" and "developing revenue model for existing social products/ services offerings" could be grouped into a node labeled "building commercial revenue-generating mechanisms". This led to the development of second-order themes regarding various kinds of institutional works that enable the incorporation of commercial processes within traditional NPOs (providing meaning and focus to each theme). We then drew from the three aspects of the institutional entrepreneurship perspective of organizational transformation ${ }^{7}$ to categorize

\footnotetext{
7 We careful reviewed the relevant literature and identified three aspects of the institutional entrepreneurship perspective of organizational transformation: (1) introducing new practices to exploit fresh opportunities, (2) developing new organizational structures and oper-
} 


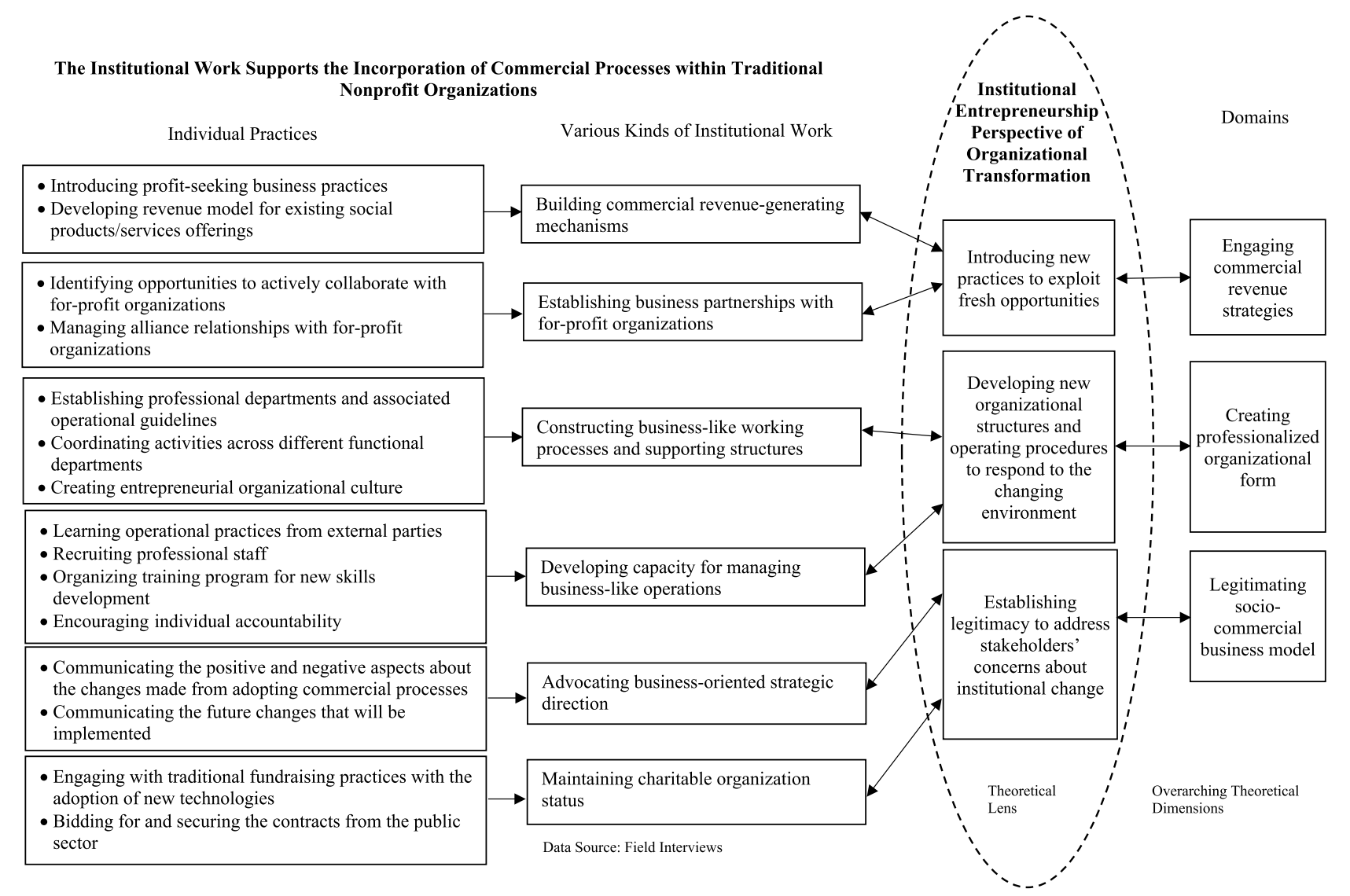

Fig. 1 Data structure

these different kinds of institutional work into three domains (aggregate theoretical dimensions) - (1) engaging commercial revenue strategies, (2) creating a professionalized organizational form, and (3) legitimating socio the-commercial business model-which summarize how traditional NPOs transform into SEs.

To ensure the trustworthiness of our data analysis, we (multiple authors) each coded the data separately following the same steps and assessed each other's coding. We discussed codes and categorization until an agreement was strong. When there was a disagreement, we discussed it and modified the entire category under question. Afterward, we invited a colleague to act as an external coder to sort and code a random sample of 13 interviews (roughly 25\%) using our category template to establish inter-coder reliability. We achieved a reliability rating of $93.4 \%$ by dividing the number of agreed coding by the total number of coding (agreed and

\section{Footnote 7 (continued)}

ating procedures to respond to the changing environment, and (3) establishing legitimacy to address stakeholders' concerns about institutional change. disagreed). We discussed the remaining differences with this external coder and reached an agreement about them. Ultimately, the reliability of our data analysis was established. Figure 1 illustrates our final data structure.

\section{Findings}

\section{Engaging Commercial Revenue Strategies}

Prior research on institutional entrepreneurship emphasizes that the engagement of organizational transformation usually starts with the introduction of new practices to exploit fresh opportunities (Greenwood and Suddaby 2006; Maguire et al. 2004). In line with this aspect of institutional entrepreneurship, our analysis suggests that the incorporation of commercial processes within traditional NPOs involves the engagement of commercial revenue strategies. Institutional entrepreneurs perform two types of institutional work. The first type is to build commercial revenue-generating mechanisms. On the one hand, the focus of institutional entrepreneurs is to introduce new profit-seeking business practices. One of our interviewees related the following: 
We have opened several retail shops on the high street throughout as we see a business opportunity here. [...]. We generate income by selling new and donated goods in our shops as well as recycling some donated goods. We have developed a separate commercial arm [that has staff with high street retail experience] to manage it like a commercial retail company. (CEO, General Purpose)

Another interviewee offered a different example of profitseeking practice:

We have various commercial income-generating methods. For example, we operate a café and restaurant. [...]. What we have done here is to establish a new trading company to handle this kind of activity. (Head of Finance, Others)

On the other hand, institutional entrepreneurs engage in the action of developing a revenue model for existing social products/services offerings. An interviewee from a theatre charity provided the following example:

One of our income streams is to provide training to teachers and practitioners. [...]. We offered a 2-3 day intensive [training] course. They [the trainees] also have the opportunities to come into projects [theatre work] with us and learn from us. [...]. Our CEO is in charge of this [training] program, and we all offer input into it. (Administrator, Art/Culture)

By engaging in both kinds of revenue-generating mechanisms, traditional NPOs can earn income from commercial practices in supporting their social mission (Arrow 2000; Sanders and McClellan 2014). The key differences are that the former approach emphasizes selling goods and services that do not relate to their charitable practices (i.e., operating retail stores and café restaurant), but the latter approach earns additional income from offering goods and services that relate to their charitable practices (i.e., theatre performing training). It is not surprising to find that traditional NPOs seek any commercial opportunities to generate revenue via this former approach (profit-seeking business practices separate from charitable practices), such movement has been explicitly mentioned in previous studies (Kerlin and Pollak 2011; Liu and Ko 2014; Maier et al. 2016). However, it is interesting to find that many traditional NPOs start to develop a revenue model by offering goods and services that relate to their charitable practices. This latter approach allows traditional NPOs to leverage their knowledge and expertise in providing social products/services and convert them into business opportunities.

In general, this form of institutional work focusses on introducing new practices that help to redirect organizations' attention towards developing new organizational structures (e.g., commercial arm, trading company) and management practices (e.g., CEO's direct charge) to cope with them (Greenwood and Suddaby 2006; Tracey et al. 2011). Thus, the building of commercial revenue-generating mechanisms not only means that traditional NPOs are less dependent on voluntary revenue sources but also drives the tendency to build new organizational forms to explore new revenue sources aggressively.

The second type of institutional work is to establish a business partnership with for-profit organizations. This reflects the movements to establish cross-sector alliances between traditional NPOs with for-profit organizations (e.g., Liu et al. 2018; Sakarya et al. 2012). In these relationships, traditional NPOs can obtain financial support from for-profit organizations. Our analysis shows that institutional entrepreneurs focus on identifying opportunities to actively collaborate with for-profit organizations. An interviewee explained,

We are very partnership-focused. Almost all of the projects we do, we try to find partners (i.e. corporate partners ...) to collaborate with and deliver them. As a result, we have developed a very sophisticated system [e.g., location, project types, brand image, etc.] to acquire and match partners on different projects. (Director, General Purpose)

The collaborative relationships between traditional NPOs and for-profit organizations have been well researched by scholars in the field (Austin and Seitanidi 2012a, 2012b). Recent research shows that such relationships not only offer potential revenue-generating opportunities for traditional NPOs but also, more importantly, enable them to develop a wide range of new business and management capabilities via the processes of collaboration (Ko and Liu 2015; Liu and Ko 2012). As a result these traditional NPOs become more capable of organizing and executing commercial practices.

Once the alliance is formed, the next important step is to manage the alliance relationship with for-profit organizations. This is not an easy task because traditional NPOs and for-profit organizations may face different demands from these alliance relationships and different ways to operate joint-activities (Liston-Heyes and Liu 2013; Liu and Ko 2011). Therefore, institutional entrepreneurs need to find ways to accommodate the needs of for-profit organizations in order to sustain the alliance relationship. An interviewee explained his situation:

Once you get some companies to support you, then that makes it easier, but it is also I think most of the relationships that have developed over the long term are because we have done business with them as well. Nevertheless, we have a corporate fundrais- 
ing team [department] to manage our relationship with the companies and keep our eyes on the new companies [that we can partner with]. (CEO, Education/Youth)

Central to this form of institutional work is that institutional entrepreneurs need to think beyond the current institutional arrangements (Greenwood and Suddaby 2006) and realize the benefits in this kind of alliance relationship (Sakarya et al. 2012). Our analysis suggests that institutional entrepreneurs tend to develop systematic approaches to manage this cross-sector alliance relationship. These findings are in line with recent research on managing the relationship between traditional NPOs and for-profit organizations (e.g., Le Pennec and Raufflet 2018; Liu et al. 2018). As it is easier and more cost-effective to expand the current business partnership scope or start a new commercial arrangement with existing for-profit organization partners than find new ones (Al-Tabbaa et al. 2019), traditional NPOs should focus on developing long-term cross-sector alliance relationships. Together, the actions of forming and maintaining cross-sector alliance relationships represent traditional NPOs' efforts to actively seek opportunities to generate revenue from collaborating with for-profit organizations.

\section{Creating a Professionalized Organizational Form}

In order to introduce new practices to obtain commercial income outlined in the previous section, institutional entrepreneurs need to consider new organizational structures and operating procedures because the existing arrangements prevent traditional NPOs from performing these practices effectively. As a result, field experts suggest that institutional entrepreneurs need to create a professionalized organizational form to cope with these newly developed commercial practices (Broadbridge and Parsons 2003; Hwang and Powell 2009). Through the theoretical lens of institutional entrepreneurship, our analysis identifies two types of institutional work. The first type involves constructing business-like working processes and supporting structures. In so doing, our analysis suggests that institutional entrepreneurs should apply three significant changes to the existing institutional arrangements.

First, institutional entrepreneurs can guide the staff's behaviors and actions toward professionalization by establishing professional departments and associated operational guidelines. We use the term "professional department" to indicate the specific functional department (i.e., marketing department) within NPOs, which is mainly run by staff who have been trained and have the relevant skills (expertise) to perform job functions in the area of specialism. An interviewee explained that some business functions (such as fundraising) need to be professionally executed which can improve their operating effectiveness and efficiency:

We have a Corporate Fundraising Department. [...]. We have dedicated individuals to handle community fundraising, membership subscriptions, and other corporate fundraising initiatives. [...]. This movement [establishing corporate fundraising department] enhances the effectiveness of corporate fundraising and helps us to compete with others (i.e. for-profit and other nonprofit organizations). (Director of Resource, General Purpose)

To support the newly established professional department, an interviewee also pointed out the importance of associated operational guidelines to guide staff behaviors and actions:

After setting up a Business Development Department, we put together some staff dedicated to run this department. [...]. They will spend time working very closely with Operations [Department], almost on a daily basis, helping them to develop their budgets, development plans, and talking to them about new business opportunities. It is very much a partnership arrangement between Operations and Business Development. (CEO, General Purpose)

Together, these movements allow traditional NPOs to compete with other organizations in acquiring commercial revenue in the marketplace. These findings are in line with prior literature on the benefits of traditional NPO professionalization (e.g., Broadbridge and Parsons 2003; Hwang and Powell 2009; Suarez 2010). The development of professional departments enhances the operational efficiency of traditional NPOs because staff from different departments can concentrate on specific tasks. As a result, institutional entrepreneurs can focus on optimizing the use of scarce resources for each task and ensure the quality of delivery across the organization (André and Pache 2016; Maier et al. 2016).

Second, by coordinating activities across different functional departments, institutional entrepreneurs are able to carry out new practices and avoid potential conflicts between charitable and commercial activities. The incorporation of commercial processes within traditional NPOs will lead to the creation of some business functions and practices (i.e., corporate fundraising) that are dramatically different from the traditional NPOs' existing ones. Our analysis suggests that NPOs need to develop the ability to ensure cross-departmental coordination. One approach is to establish centralized control mechanisms to oversee the entire operation. An interviewee explained his situation: 
We have a Strategy Group that meets on a regular basis and oversees the entire operation. It ensures that different parts of the operation in our new [organizational] structure can work well together. (Operation Manager, Health/Aid Relief)

Another approach is to achieve cross-functional departmental coordination via developing robust internal communication mechanisms (i.e., meetings) to ensure that information flows freely within the organization. One interviewee stated:

We organized a monthly meeting, and that is for all staff, led by the Chief Executive. At that point, we always talk about what we are doing next but, equally, it is an opportunity for all members to tell us what is coming up for them as well. So, it is a real sharing opportunity. [...]. Anyone can ask any questions or share their ideas. (Commercial Director, Art/Culture)

Scholars have raised concerns that SEs' operations are driven by the pursuit of efficiency and specialization (André and Pache 2016; Staessens et al. 2019). Such a pursuit may cause parts (some staff) of the SEs to not focus their attention on creating social impact and to abandon the organizations' social missions. As a result, institutional entrepreneurs need to fine-tune the coordination processes to connect different specialized functional departments (André and Pache 2016; Battilana et al. 2015). Our findings reflect this aspect of organization transformation and point out traditional NPOs' efforts to set up coordinating activities across different functional departments when incorporating commercial processes. These findings echo the observations from earlier works on hybrid business model development, which call attention to the importance of cross-departmental coordination for accommodating dual commercial and social foci (Cooney 2006; Pache and Santos 2013).

Third, organizational culture is delineated as the fundamental assumptions that people share about an organization's values and beliefs that give meaning to the organizational membership, and that guide behavior (Tyler and Gnyawali 2009). We choose "entrepreneurial culture" as the label because our interviewees consistently referred to "opportunities-seeking" or "accepting failure/risk" as the fundamental assumptions for this value/belief system (Nicholls 2008; Tracey et al. 2011). Throughout the interviews, a consistent pattern emerged, showing that the interviewees viewed the installation of entrepreneurial culture as the foundation upon which traditional NPOs can effectively incorporate commercial processes:

In terms of culture change, even though the incomegeneration is the responsibility of a couple of us, everyone in the organization is very much aware of the fact that we need to be looking for opportunities, so most people have become more entrepreneurial. (CEO, General Purpose)

I am building a new culture here. It is a learning culture. It is a culture of quality, in terms of our provision. It is an open culture, and it is a culture where failure is acceptable, but we want to learn from failure. (CEO, Education/Youth)

The processes of transforming from traditional NPOs to SEs often encounter many challenges (Fitzgerald and Shepherd 2018; Maier et al. 2016). As each traditional NPO has a different history, charitable objective, and processes to carry out business operations, there is no "right" approach to accommodating commercial processes within social organizations. Instead, there will be a great deal of trial and error to find the most suitable approach (Ko and Liu 2015; Liu and Ko 2012). Entrepreneurial culture, from this perspective, embraces and emboldens such focus. Creating such a culture enables institutional entrepreneurs to instill new values and beliefs among the staff regarding the importance of finding new and creative ways to pursue commercial business opportunities that are most suitable for the conditions of specific traditional NPOs.

The second type of institutional work is developing capacity for managing business-like operations. In addition to constructing business-like working processes and supporting structures, our analysis found that institutional entrepreneurs also focus on ways to manage them effectively. One approach is to learn management techniques from other SEs. An interviewee explains how her organization is learning operational practices from other SEs:

One important area is to engage expertise outside of the organization to be able to support us to do that. We are part of a network called XXX [a social enterprise network body]. [...]. We gather other social enterprises with similar business practices to exchange information and knowledge and hopefully will be able to build our capacity for growing the business. (Training and Development Manager, General Purpose)

She further provided an example of what her organization has learned about managing a cross-sector alliance:

We learn [from other SEs] on how to manage this relationship [the partnership between for-profit and traditional NPOs] and to work in a way that the corporation understands. [...]. It is all about communication, getting things done very quickly, being quite flexible, and obviously understanding the cost of our activities and accepting that it is not just the fact that they are giving their staff [employee volunteer] to the project. (Training and Development Manager, General Purpose) 
Through repeatedly engaging in fundraising and administrative tasks related to charitable activities, traditional NPOs develop a sophisticated knowledge-base in running social organizations (Bish and Becker 2016). However, such knowledge is context-specific and cannot be easily applied to operate hybrid organizations. As a result, traditional NPOs need to learn (acquire) a new set of knowledge. Our findings reveal that the mode of learning from external parties captures the acquisition of a new set of knowledge on how to perform specific operational activities that are important for the newly emerging organization form, which is novel to traditional NPOs (Ko and Liu 2015; Liu and Ko 2012).

Other than learning from others, institutional entrepreneurs can also "buy-in" new management knowledge by recruiting professional staff and organizing training programs for new skills development. In this aspect, knowledge is embedded in individuals' experience in performing specific tasks (Akingbola 2006; Hwang and Powell 2009). Unsurprisingly, NPOs face challenges regarding (lack of) knowledgeability about conducting business operations in the new organization form (i.e., SEs). On the one hand, institutional entrepreneurs can resolve this challenge by designing recruiting practices to target individuals who already hold the suitable skills:

We need someone that feels very comfortable with technology, to be inquisitive and curious. We also need someone who has good financial skills. [...]. Someone who can work at a very fast pace. (CEO, General Purpose)

On the other hand, institutional entrepreneurs can train existing staff to develop skills that are suitable for managing the new organization form. The emphasis here is to establish training programs to systematically teach and coach staff who, currently, lack knowledge about performing the new tasks demanded in the new organization form:

We are getting a lot more [training] in softer leadership skills, customer focus [thought processes], user involvement focus [thought processes], and others. [...]. We are not only just to get people to think about how and why they do it [performing SE-related tasks] but how they can do it differently, how they view the outside world. [...]. So, they are far more astute, I suppose in those leadership and business understandings. (Human Resource Director, General Purpose)

At a deeper level, the training represents adaptation and dissemination of information about how the organization should be operated that is very different from traditional NPOs' existing strategy. Recent research on human resource management practices advocates that SEs should take into account their unique hybrid organization context when managing their workforce (Hsieh et al. 2018; Roumpi et al.
2019). Our findings echo this perspective by indicating the approaches that institutional entrepreneurs take to reconstruct their organization-specific human capital by recruiting external experts and training existing staff. Such practices are employed to ensure that staff within the newly emerging SEs have the capacity to manage this new organizational form and all related aspects.

Lastly, our analysis found that institutional entrepreneurs could encourage individual accountability to improve management efficiency. The core idea was to convey that each staff member has a specific role to play in the new organizational form and has the obligation to ensure that he or she fulfills the tasks demanded by the role. An interviewee stated:

We need to be much more accountable for our work.

Our staff used to work in environments that are very hierarchical with very low levels of personal accountability. [...]. So, I set up processes to monitor and evaluate individual staff's practices. (CEO, Education/ Youth)

He further explained the processes that he has put in place for the organization:

We have monitoring and evaluating structures, not only for finances but also in terms of practice. [...]. We monitor and track the progress of our project completion and the overall quality assurance that the management structure is. We have adopted an international quality standard [ISO 9001]. We went through that last year, and that has gone all the way through all of our management processes in a very detailed way. [...]. So the ISO 9001 stamp is something that we use in contracting to show that we are an organization of a certain level, and we can handle larger contracts. (CEO, Education/Youth)

The introduction of specific performance monitoring and evaluating mechanisms can encourage individual staff to be more accountable for their output. Although this does not suggest that traditional NPOs do not hold their staff accountable for their work, our observation nevertheless indicates that institutional entrepreneurs tend to give an individual staff member a higher level of accountability for delivering results to ensure that they are doing what is required of them in the new organization form. As the operational processes of the organization become more complex (i.e., interaction of social and commercial operations), institutional entrepreneurs need to introduce more management tools (e.g., performance indicators) in order to ensure levels of quality and efficient delivery of the social/commercial products/ services (Liu and Ko, 2014; Roumpi et al., 2019). This will, inevitably, lead to the organizational move of demanding that staff be accountable for their actions and performance. 


\section{Legitimating Socio-commercial Business Model}

Drawing on the institutional entrepreneurship perspective, scholars have emphasized the importance of establishing legitimacy for organizational transformation (Greenwood et al. 2010; Maguire et al. 2004). This is because the essence of organizational transformation is to repurpose the use of resources supplied by the organizations' stakeholder groups. As a result, institutional entrepreneurs need to address stakeholders' concerns about institutional change in order to continue accessing the resources (Desa 2012; Maguire et al. 2004). Our analysis suggests that institutional entrepreneurs undertake two types of institutional work to legitimate the socio-commercial business model for the newly emerged SEs. We use the term 'sociocommercial business model' to describe an operational logic that accommodates commercial processes within social organizations (Fitzgerald and Shepherd 2018; Pache and Santos 2013).

The first type of institutional work is advocating the business-oriented strategic direction; it aims to address stakeholders' concerns about the engagement of commercial revenue strategies. Traditional NPOs often face the challenges of losing some stakeholders' support when attempting to raise funds via commercial revenue strategies. To illustrate, Herman and Rendina (2001) suggest that traditional NPOs can lose the financial support from their donor(s) when they raise additional funds via commercial activities because these donors view such activities as not consistent with, or that they do not advance, the NPO's social mission. To legitimate engaging in commercial revenue strategies, institutional entrepreneurs focus on communicating the reasons for adopting such strategies. An interviewee suggested:

We tell our donors and volunteers [stakeholders] honestly about our situations [lack of funding] and explain to them that we need more funds to support what we are doing in retailing [charity shops] and business partnership [corporate sponsorship]. [...]. They usually understand why we are doing this [adopting trading practices and corporate partnership]. (Chief Executive, General Purpose)

She further explained the importance of communicating to stakeholders the institutional changes implemented from adopting commercial revenue strategies:

We have a breakfast meeting every month. We invite our stakeholders (i.e., donors, business partners, etc.) and our staff to join us. The team of executives will update everyone about what is going on, the good, the bad, the ugly, what we are focussing on, and what our key challenges might be. [...]. I will then write a monthly bulletin to everyone [who is not in the meeting] to do exactly the same thing. (Chief Executive, General Purpose)

Our analysis revealed that institutional entrepreneurs regularly communicate both the positive aspects (the changes that stakeholders are likely to approve of) and the negative aspects (the changes that stakeholder are not likely to approve of). One of the critical challenges that traditional NPOs face when incorporating commercial processes and becoming "business-like" SEs is to justify their movements to the existing (e.g., donors, volunteers, etc.) and new (e.g., customers, business partners) stakeholders (Nicholls 2010; Yang and $\mathrm{Wu}$ 2016). This is often difficult as SEs face diverse and sometimes conflicting expectations and demands from stakeholder groups. Focussing on communicating the positive and negative aspects of organizational transformation instead of only disseminating the positive side of the change allows the newly formed SEs to gain the trust of stakeholders by demonstrating that they are not trying to hide anything from them. This is consistent with prior studies that highlight the important role that communication plays for NPOs to gain stakeholders' approval to conduct commercial activities (Liston-Heyes and Liu 2013; Sanders 2015).

Furthermore, this approach also sets the stage for further negotiating with stakeholders about the upcoming changes that will be implemented by the institutional entrepreneurs:

We are always talking about what we are going to do next with our staff on a regular basis. Equally, we invite them to tell us what they think and feel about the changes we made. We want to make sure that everyone is on the same page. (Commercial Director, General Purpose)

In doing so, institutional entrepreneurs can shape stakeholders' expectations about the new practices, which in turn establishes legitimacy. Nevertheless, they will inevitably face conflicts of interest from different stakeholders because different stakeholders will have different demands (Cooney 2006; Sanders 2015). For example, an interviewee suggested the following:

There is a potential for conflict because if customers [from retail store], beneficiaries [from care service], and donors [from fundraising activities] all wanted to pull on that resource at the same time. [...] We would prioritize [their demands] between ourselves and deal with them accordingly. (Deputy CEO, General Purpose)

In the process of transforming from a social to a sociocommercial (hybrid) business model, traditional NPOs will face more diverse and conflicting demands from their 
stakeholder groups (Fitzgerald and Shepherd 2018). To overcome this challenge, our analysis suggests that institutional entrepreneurs need to take an active role in prioritizing their demands and deal with them one by one. This approach is in line with other scholars' recommendations on how SEs should address the expectations of multiple stakeholder groups to establish organizational legitimacy (Ramus and Vaccaro 2017; Yang and Wu 2016). In general, our data reveal institutional entrepreneurs' efforts to communicate future changes in order to manage the legitimacy of their socio-commercial business model.

The focus of the second type of institutional work is on maintaining social organization status. This type addresses stakeholders' concerns on the creation of a professionalized organizational form. Before venturing into commercial practices, the primary sources of revenue for traditional NPOs are private donation and government funding. Still, SEs usually appreciate that the higher percentage of funding coming from these two sources of revenue increases their legitimacy profile (Froelich 1999). According to our analysis, the focus of institutional entrepreneurs is to communicate to stakeholders that the newly emerging SEs will continue to raise funds from these two sources of revenue. More importantly, institutional entrepreneurs demonstrate to stakeholders that this professionalized organizational form can obtain funds from these revenue sources more effectively and efficiently.

In particular, prior studies recognize that applying new technology to raise funds from nonprofit sources can both improve fundraising results and maintain legitimacy (e.g., Hackler and Saxton 2007; Saxton and Wang 2014). In line with these studies, an interviewee reported that his organization developed the use of IT-based consumer relationship management systems to manage its donors' information:

We have recently taken ownership of our own box office and adopted a new [information technology] system such as CRM [customer relationship management] platform to manage it. This allows us to have a direct dial-up with our ticket buyers and donors. It has made a difference. (Financial Director, Art/Culture)

Another interviewee explained the use of digital space for engaging crowd-funding activities:

We have got a digital space put up, and we could do crowd-funding - somebody just the other week came up with an idea. For example, we can do some filming inside one of the old clinics and then show them the new clinic and we could crowd-fund for that and people could go in and explore the spaces, and they could see what they could crowd-fund for $£ 50$ buys medicines or $£ 100$ buys a medical pack, or whatever."(Fundraising Manager, Health/Aid Relief)
These pieces of evidence suggest that the possession of competence to integrate new technologies into traditional NPOs' existing operating activities is important to improve the effectiveness of their fundraising practices (Raman 2016; Tung and Jordann 2017). This approach allows institutional entrepreneurs to show stakeholders that this professionalized organizational form is more capable of engaging with traditional fundraising practices with the adoption of new technologies, as two interviewees similarly explained:

I do not find it difficult to justify [to stakeholders] what we have done [creating a professionalized organizational form] because they can see that we are still the nonprofit [organization] that they knew." (Financial Director, Art/Culture)

"I think that action speaks louder than words. [...]. We are still the same organization [NPO] as before. But now, we are able to raise more funds for our work [social mission]. (Fundraising Manager, Health/Aid Relief)

Funding from the government represents an important source of income for traditional NPOs. Even though the government has cut direct funding support for traditional NPOs (Laforest 2013; Maier et al. 2016), it is starting to package some public services into different scales of deliverable public contracts. Our analysis suggests that institutional entrepreneurs view this as an important opportunity to show stakeholders that their professionalized organizational form is more capable of securing this type of government contract and legitimatizing this organizational transformation. An interviewee explained:

[...] what is happening is that the government is looking for and are asking people to tender for larger contracts, but there are fewer providers [...]. The scale of the contract is very large. We will not be able to do it alone. So, we work with very specialist groups of people, so we can work together almost as an alliance and a partnership, to be able to put funding bids in together. (Head of Development, General Purpose)

The interviewee further indicated:

We are not able to do this [bid for this type of government contract] before the restructuring. [...]. This helps to clear all the naysayers' [stakeholders who criticize the professionalized organizational form] doubts about our restructuring. (Head of Development, General Purpose)

An essential element of securing public sector contracts is to demonstrate the organization's capability to successfully deliver specific public services. SEs with more a professionalized organizational form than traditional NPOs are more capable of delivering such services because they can 
perform the tasks more effectively and use their connections with for-profit organizations to acquire more resources (e.g., knowledge, expertise, financial support, etc.) from them (Powell et al. 2019; Vickers et al. 2017). Therefore, SEs are more likely to develop a great public service proposal, which in turn improves the odds of winning the government contract bid. Through bidding for and securing the contracts from public sectors, institutional entrepreneurs demonstrate to stakeholders that the newly formed SEs still focus on the pursuit of social missions like other social organizations do. This, subsequently, legitimatizes institutional entrepreneurs' efforts to create a more professionalized organizational form.

\section{Discussion and Concluding Remarks}

\section{Theoretical Contributions}

The research question of this study is how SEs are transformed from traditional NPOs via incorporating commercial processes within social organizations in the first place? To answer this question, we conducted and analyzed 64 field interviews with institutional entrepreneurs from UK-based SEs. We found that the transformation from traditional NPO to SE involves three domains of institutional work: (1) engaging commercial revenue strategies, (2) creating a professionalized organizational form, and (3) legitimating the social-commercial business model. In developing our arguments, we make four significant contributions.

First, this study extends extant institutional entrepreneurship literature to the SE context by showing that different domains of institutional work are required when institutional entrepreneurs incorporate commercial practices within social organizations to transform traditional NPOs to SEs. The findings indicate that organizational transformation starts with the engagement of commercial revenue strategies to raise additional funds to support the organizations' social missions. It involves institutional entrepreneurs building commercial revenue-generating mechanisms to obtain funds from commercial activities or establishing business partnerships with for-profit organizations to seek corporate financial support.

Because the traditional NPOs' current organizational form cannot effectively implement both practices, institutional entrepreneurs construct a professionalized organizational form to improve the organizations' competitiveness in implementing commercial revenue strategies. Specifically, institutional entrepreneurs construct business-like working processes and supporting structures that offer a strong foundation for organizations to exploit new commercial opportunities. Institutional entrepreneurs also develop managerial capacity business-like operations that enable organizations to manage their newly emerged operations more effectively.
To end, institutional entrepreneurs carry out two types of institutional work to legitimate SEs' socio-commercial business model. On the one hand, they advocate SEs' business-oriented strategic directions to stakeholders to justify the rationale for engaging in commercial revenue strategies. On the other hand, they focus on maintaining social organization status to overcome stakeholders' resistance to change. Together, these domains of institutional work resonate with some recent research on organizational transformation from the institutional entrepreneurship perspective (e.g., Greenwood and Suddaby 2006; Maguire et al. 2004; Rao and Singh 2001). However, our specific focus on the transformation from traditional NPO to SE allows us to extend this work by explicitly showing how institutional entrepreneurs accomplish reforms of traditional NPOs. Our work thus suggests a more complex and less linear picture of how commercial processes are incorporated within social organizations.

Second, with a few exceptions (e.g., Desa 2012; Tracey et al. 2011), recent studies on SE formation have overlooked the practice of how traditional NPOs incorporate commercial processes and transform into SEs. Most scholars in this research area focus on understanding how SEs attempt to deal with the challenges of balancing dual commercial and social objectives after the formation of SEs (e.g., Battilana et al. 2015; Fitzgerald and Shepherd 2018; Pache and Santos 2013; Wry and York 2017). Put simply, scholars have paid much more attention to the ex-post scheme of managing hybrid organizations than the "ex-ante" plan of their creation. Our analysis highlights numbers of "individual practices" (see Fig. 1) that are undertaken by institutional entrepreneurs to support the transformation from traditional NPOs to SEs. In sum, we believe that our findings show that the formation of SEs needs institutional entrepreneurs to engage in a series of individual practices to incorporate commercial processes within social organizations. Thus, the formation of SEs is a complex activity. From our findings, we thus provide a comprehensive picture of the emergence of SEs from traditional NPOs.

The third contribution pertains to the research methodology. It is evident that most scholars studying the formation of SEs tend to use a single case or small numbers of case studies as their primary research method (e.g., Fitzgerald and Shepherd 2018; Pache and Santos 2013; Tracey et al. 2011; Vickers et al. 2017). Although this methodological approach allows scholars to build an understanding from the properly contextualized experiences of those individuals involved in particular SEs' creation and operations, it subsequently limits the conclusions that they can infer across different SE sectors. Our research incorporates institutional entrepreneurs' experiences from multiple SE sectors and provides a more generalized insight into the nature of this phenomenon. 
Finally, our work contributes to the discussions of business ethics in the area of social entrepreneurship (e.g., Bacq et al. 2016; Bull and Ridley-Duff 2019; Chell et al. 2016). In particular, scholars indicate that SEs often over-emphasize revenue generation, efficiency, and specialization (André and Pache 2016; Cooney 2011). Such an approach, however, will ultimately divert the attention of the SEs from pursuing social missions. Scholars challenge SEs' ethical stance in that, by focussing on serving resources providers (e.g., customers), they may run the risk of providing less attention to their beneficiaries (e.g., underprivileged individuals or groups) (André and Pache 2016; Battilana et al. 2015; Staessens et al. 2019). This type of ethical concern is particularly relevant to traditional NPOs in the process of transforming into SEs. Unlike other forms of SEs (i.e., organizations that focus on finding innovative ways to solve social problems or providing social products and services to benefit the community) that may have either profit-seeking or philanthropic motives, at the heart of the traditional NPO is the intent to achieve their social missions (Defourny and Nyssens 2012; Weerawardena and Mort 2012).

This may indirectly explain why some institutional entrepreneurs refuse to consider their organizations as SEs despite the fact that the revenue model of their organization fits our definition of SEs. Perhaps, these institutional entrepreneurs want to prioritize their organizations' focus on attending to the demands of beneficiaries and avoid mission drift. By continuing to consider their organizations as traditional NPOs, these institutional entrepreneurs concentrate their attention on achieving their social mission. As we did not collect any direct pieces of evidence relating to this issue, such a presumption may need to be studied further. That said, our findings offer a tool for scholars in this field to examine in greater depth each individual practice that forms various kinds of institutional work related to how traditional NPOs incorporate commercial processes. Scholars can now debate the connection of (or disconnection from) each individual practice to different ethical perspectives. This opens up possibilities for posing more specific ethical questions about the transformation from traditional NPOs to SEs.

\section{Management Implications}

This research has some useful implications for managers within traditional NPOs, who wish to raise funds from commercial sources. First, we identified three domains of institutional work that enable managers to incorporate commercial processes within traditional NPOs. Our work thus offers an important overview for NPO managers regarding the key areas that they need to focus their attention on when planning for this organizational transformation. More specifically, when managers decide to become institutional entrepreneurs to transform traditional NPOs to SEs, they can concentrate their efforts on engaging commercial revenue strategies, creating a professionalized organizational form, and legitimating the social-commercial business model.

Second, we identified six distinct kinds of institutional work (at three different domains) and individual practices that support each kind of institutional work. Our work, thus, provides concrete guidelines for managers of traditional NPOs on how to incorporate commercial processes within their organizations. For example, if managers want to lead their organizations to engage commercial revenue strategies, they need to make plans to build commercial revenue-generating mechanisms and establish business partnerships with for-profit organizations. To build commercial revenue-generating mechanisms, NPO managers need to engage in two individual practices: (1) introduce profit-seeking business practices and (2) develop a revenue model for existing social products/services offerings. To establish business partnerships with for-profit organizations, NPO managers also need to focus on two other practices; (1) identify opportunities to actively collaborate with for-profit organizations and (2) manage alliance relationships with for-profit organizations.

\section{Limitations and Future Research Directions}

First, the narrow generalizability of findings is a limitation of this study. The study conclusions are based on 64 field interviews from different SE sectors in the UK. Although our qualitative research approach is stronger than previous works using a single case or small numbers of case studies in terms of offering a more generalizable view on the formation of SEs, we still need to recognize the limitation that our data were collected from a sample within a single country (UK). Future studies can use large quantitative surveys to test our findings in different countries to further establish generalizability. Furthermore, we did not find that sector differences have any influence on our findings. Nevertheless, we still need to recognize that we drew our conclusion from analyzing a small sample of SEs. Future research should adopt large-scale databases to confirm whether the SE sector has any influence on the transformation from traditional NPOs to SEs.

Second, our research does not generate any quantitative measurements. For example, we recognize that it is crucial for institutional entrepreneurs to construct business-like working processes and supporting structures. However, our datasets cannot provide a precise quantitative scale to reflect the exact degree of such importance. Future research can explore the weight of the different kinds of institutional work. Furthermore, the development 
of a metric scale for different kinds of institutional work would also open up new avenues for quantitative research opportunities.

Third, based on our definition of SEs in this research, we identify SEs as organizations that have generated commercial revenue and are registered as social organizations. Although this approach allows us to differentiate between traditional NPOs and SEs, we are, however, still uncertain about whether the traditional NPOs are "working-in-progress" to continue incorporating more functions to support commercial practices or whether they have "successfully" integrated commercial processes into their business models. As organizations (includes all types of organization such as SEs) need to continuously reconfigure their operational procedures to survive in the ever-changing business environment (Teece 2007), we presume there may never be a point in time where traditional NPOs have "completed" their transformation and face no future challenges. Nevertheless, future research should adopt a longitudinal method to observe the SEs over a period of time to offer a more complete picture of the transformation from traditional NPOs to SEs.

Finally, our findings also reveal other future research opportunities. As we have now identified the individual practices that form various kinds of institutional work related to how traditional NPOs transform to SEs, further research can be designed to explore barriers and challenges faced by traditional NPOs to perform each of the individual practices, as well as how institutional entrepreneurs attempt to solve these problems creatively. The findings of such future research can yield theoretical implications on the concept of institutional entrepreneurship in the field of social enterprises (e.g., Chatzichristos and Nagopoulos 2019; Tracey et al. 2011) and managerial practices on the incorporation of commercial processes within social organizations. We hope that further research continues to explore and document the processes of transforming from traditional NPOs to business-like SEs.

\section{Conclusion}

Overall, we find it surprising that scholars have paid relatively little attention to the practices of transforming traditional NPOs to SEs. This kind of institutional entrepreneurship appears increasingly widespread today due to the reduction of private donations and government funding and the increasing competitiveness among organizations in the third sector. We believe our study constitutes an important step in building more understanding of how SEs are transformed from traditional NPOs via incorporating commercial processes within social organizations.

Funding This study was funded by the British Academy (Grant Number: SG162991).

\section{Compliance with Ethical Standards}

Conflict of interest The authors declares that they have no conflict of interest.

Ethical Approval All procedures performed in studies involving human participants were in accordance with the ethical standards of the institutional and/or national research committee and with the 1964 Helsinki declaration and its later amendments or comparable ethical standards.

Research Involving Human and Animal Rights This article does not contain any studies with animals performed by any of the authors.

Informed Consent Informed consent was obtained from all individual participants included in the study.

Open Access This article is licensed under a Creative Commons Attribution 4.0 International License, which permits use, sharing, adaptation, distribution and reproduction in any medium or format, as long as you give appropriate credit to the original author(s) and the source, provide a link to the Creative Commons licence, and indicate if changes were made. The images or other third party material in this article are included in the article's Creative Commons licence, unless indicated otherwise in a credit line to the material. If material is not included in the article's Creative Commons licence and your intended use is not permitted by statutory regulation or exceeds the permitted use, you will need to obtain permission directly from the copyright holder. To view a copy of this licence, visit http://creativecommons.org/licenses/by/4.0/.

\section{Appendix}

See Table 1.

Table 1 Interviewees

\begin{tabular}{lcccc}
\hline Sectors & $\begin{array}{l}\text { General } \\
\text { administra- } \\
\text { tion }\end{array}$ & $\begin{array}{l}\text { Fundraising } \\
\text { or marketing }\end{array}$ & $\begin{array}{l}\text { Commer- } \\
\text { cial affairs }\end{array}$ & Total \\
\hline General purpose & 15 & 2 & 5 & 22 \\
Art/culture & 7 & 1 & 1 & 9 \\
Education/youth & 10 & 1 & 1 & 12 \\
Health/aid relief & 3 & 3 & 2 & 8 \\
Others & 8 & 3 & 2 & 13 \\
Total & 43 & 10 & 11 & \\
\hline
\end{tabular}

$\mathrm{N}=64$ 


\section{References}

Akingbola, K. (2006). Strategy and hrm in nonprofit organizations: Evidence from Canada. The International Journal of Human Resource Management, 17(10), 1707-1725.

Al-Tabbaa, O., Leach, D., \& Khan, Z. (2019). Examining alliance management capabilities in cross-sector collaborative partnerships. Journal of Business Research, 101, 268-284.

André, K., \& Pache, A.-C. (2016). From caring entrepreneur to caring enterprise: Addressing the ethical challenges of scaling up social enterprises. Journal of Business Ethics, 133(4), 659-675.

Arrow, K. J. (2000). To profit or not to profit: The commercial transformation of the nonprofit sector. Cambridge, UK: Cambridge University Press.

Austin, J. E., \& Seitanidi, M. M. (2012a). Collaborative value creation: A Review of Partnering between Nonprofits and Businesses. Part 2: Partnership processes and outcomes. Nonprofit and Voluntary Sector Quarterly. https://doi.org/10.1177/0899764012454685.

Austin, J. E., \& Seitanidi, M. M. (2012b). 'Collaborative value creation: A review of partnering between nonprofits and businesses: Part I value creation spectrum and collaboration stages'. Nonprofit and Voluntary Sector Quarterly,. https://doi.org/10.1177/08997 64012450777

Bacq, S., Hartog, C., \& Hoogendoorn, B. (2016). Beyond the moral portrayal of social entrepreneurs: An empirical approach to who they are and what drives them. Journal of Business Ethics, 133(4), 703-718.

Bacq, S., \& Janssen, F. (2011). The multiple faces of social entrepreneurship: A review of definitional issues based on geographical and thematic criteria. Entrepreneurship \& Regional Development, 23(6), 373-403.

Battilana, J., Sengul, M., Pache, A.-C., \& Model, J. (2015). Harnessing productive tensions in hybrid organizations: The case of work integration social enterprises. Academy of Management Journal, 58(6), 1658-1685.

Bish, A., \& Becker, K. (2016). Exploring expectations of nonprofit management capabilities. Nonprofit and Voluntary Sector Quarterly, 45(3), 437-457.

Bolzani, D., Marabello, S., \& Honig, B. (2019). Exploring the multilevel processes of legitimacy in transnational social enterprises. Journal of Business Venturing. https://doi.org/10.1016/j.jbusv ent.2019.1006.1002.

Broadbridge, A., \& Parsons, L. (2003). Uk charity retailing: Managing in a newly professionalised sector. Journal of Marketing Management, 7(8), 729-748.

Bruneel, J., Moray, N., Stevens, R., \& Fassin, Y. (2016). Balancing competing logics in for-profit social enterprises: A need for hybrid governance. Journal of Social Entrepreneurship, 7(3), 263-288.

Bull, M., \& Ridley-Duff, R. (2019). Towards an appreciation of ethics in social enterprise business models. Journal of Business Ethics, 159(3), 619-634.

Bush, R. (1992). Survival of the nonprofit spirit in a for-profit world. Nonprofit and Voluntary Sector Quarterly, 21(4), 391-410.

Charity Commission UK. (2016). Search for charities by their registered details. http://www.charity-commission.gov.uk/ShowCharit y/RegisterOfCharities/AdvancedSearch.aspx. Accessed Apr 2016.

Chatzichristos, G., \& Nagopoulos, N. (2019). 'Social entrepreneurship and institutional sustainability: Insights from an embedded social enterprise'. Voluntas: International Journal of Voluntary and Nonprofit Organizations. https://doi.org/10.1007/s11266-11019 -00188-11263.

Chell, E., Spence, L. J., Perrini, F., \& Harris, J. D. (2016). Social entrepreneurship and business ethics: Does social equal ethical? Journal of Business Ethics, 133(4), 619-625.
Cooney, K. (2006). The institutional and technical structuring of nonprofit ventures: Case study of a US hybrid organization caught between two fields. VOLUNTAS: International Journal of Voluntary and Nonprofit Organizations, 17(2), 137-155.

Cooney, K. (2011). An exploratory study of social purpose business models in the United States. Nonprofit and Voluntary Sector Quarterly, 40(1), 185-196.

Dalpiaz, E., Rindova, V., \& Ravasi, D. (2016). Combining logics to transform organizational agency: Blending industry and art at Alessi. Administrative Science Quarterly, 61(3), 347-392.

Dart, R. (2004). Being "business-like" in a nonprofit organization: A grounded and inductive typology. Nonprofit and Voluntary Sector Quarterly, 33(2), 290-310.

Deephouse, D. L., Bundy, J., Tost, L. P., \& Suchman, M. C. (2017). 'Organizational legitimacy: Six key questions'. In R. Greenwood, C. Oliver, T. Lawrence, \& R. E. Meyer (Eds.), The Sage Handbook of Organizational Institutionalism (pp. 27-54) Thousand Oaks, CA: Sage.

Dees, J. G., \& Anderson, B. B. (2006). Framing a theory of social entrepreneurship: Building on two schools of practice and thought. In R. Mosher-Williams (Ed.), Research on social entrepreneurship: Understanding and contributing to an emerging field (pp. 39-66). Washington, DC: Aspen Institute.

Defourny, J., \& Nyssens, M. (2012). The emes approach of social enterprises in a comparative perspective. In J. Defourny, L. Hulgard, \& V. Pestoff (Eds.), Social enterprise and the third sector: Changing European landscapes in a comparative perspective (pp. 42-65). New York: Routledge.

Defourny, J., \& Nyssens, M. (2017). 'Fundamentals for an international typology of social enterprise models'. VOLUNTAS: International Journal of Voluntary and Nonprofit Organizations. 28(6), 2469-2497.

Desa, G. (2012). Resource mobilization in international social entrepreneurship: Bricolage as a mechanism of institutional transformation. Entrepreneurship Theory and Practice, 36(4), 727-751.

Fitzgerald, T., \& Shepherd, D. (2018). Emerging structures for social enterprises within nonprofits: An institutional logics perspective. Nonprofit and Voluntary Sector Quarterly, 47(3), 474-492.

Froelich, K. A. (1999). Diversification of revenue strategies: Evolving resource dependence in nonprofit organizations. Nonprofit and Voluntary Sector Quarterly, 28(3), 246-268.

Garud, R., Jain, S., \& Kumaraswamy, A. (2002). Institutional entrepreneurship in the sponsorship of common technological standards: The case of sun microsystems and java. Academy of Management Journal, 45(1), 196-214.

Gawer, A., \& Phillips, N. (2013). Institutional work as logics shift: The case of intel's transformation to platform leader. Organization Studies, 34(8), 1035-1071.

Gioia, D. A., Corley, K. G., \& Hamilton, A. L. (2013). Seeking qualitative rigor in inductive research: Notes on the gioia methodology. Organizational Research Methods, 16(1), 15-31.

Goulding, C. (2002). Grounded theory: A practical guide for management, business and market researchers. Thousand Oaks: SAGE Publications Ltd.

Greenwood, R., Díaz, A. M., Li, S. X., \& Lorente, J. C. (2010). The multiplicity of institutional logics and the heterogeneity of organizational responses. Organization Science, 21(2), 521-539.

Greenwood, R., \& Suddaby, R. (2006). Institutional entrepreneurship in mature fields: The big five accounting firms. Academy of Management Journal, 49(1), 27-48.

Hackler, D., \& Saxton, G. D. (2007). The strategic use of information technology by nonprofit organizations: Increasing capacity and untapped potential. Public Administration Review, 67(3), 474-487.

Hardy, C., \& Maguire, S. (2017). Institutional entrepreneurship and change in fields. In R. Greenwood, C. Oliver, T. B. Lawrence, \& 
R. E. Meyer (Eds.), The Sage Handbook of Organizational Institutionalism (pp. 261-280). London: Sage.

Herman, R. D., \& Rendina, D. (2001). Donor reactions to commercial activities of nonprofit organizations: An American case study. VOLUNTAS: International Journal of Voluntary and Nonprofit Organizations, 12(2), 157-169.

Hillier, A. (2018). Number of registered charities reaches highest level in almost a decade. https://www.thirdsector.co.uk/number-regis tered-charities-reaches-highest-level-almost-decade/governance /article/1454612. Accessed Aug 2019.

Hsieh, Y.-C., Weng, J., \& Lin, T. (2018). How social enterprises manage their organizational identification: A theoretical framework of identity management approach through attraction, selection, and socialization. International Journal of Human Resource Management, 29(20), 2880-2904.

Huybrechts, B., \& Haugh, H. (2018). The roles of networks in institutionalizing new hybrid organizational forms: Insights from the European renewable energy cooperative network. Organization Studies, 39(8), 1085-1108.

Hwang, H., \& Powell, W. W. (2009). The rationalization of charity: The influences of professionalism in the nonprofit sector. Administrative Science Quarterly, 54(2), 268-298.

Ingram, P. (1996). Organizational form as a solution to the problem of credible commitment: The evolution of naming strategies among Us hotel chains, 1896-1980. Strategic Management Journal, 17(1), 85-98.

Kerlin, J. A., \& Pollak, T. H. (2011). Nonprofit Commercial revenue: A replacement for declining government grants and private contributions? American Review of Public Administration, 41(6), 686-704.

Ko, W. W., \& Liu, G. (2015). Understanding the process of knowledge spillovers: Learning to become social enterprises. Strategic Entrepreneurship Journal, 9(3), 263-285.

Laforest, R. (2013). Government-nonprofit relations in times of recession. Montreal: McGill-Queen's University Press.

Lawrence, T. B., \& Phillips, N. (2004). From moby dick to free willy: Macro-cultural discourse and institutional entrepreneurship in emerging institutional fields. Organization, 11(5), 689-711.

Le Pennec, M., \& Raufflet, E. (2018). Value creation in inter-organizational collaboration: An empirical study. Journal of Business Ethics, 148(4), 817-834.

Lewin, A. Y., Long, C. P., \& Carroll, T. N. (1999). The Coevolution of new organizational forms. Organization Science, 10(5), $535-550$.

Liston-Heyes, C., \& Liu, G. (2013). A study of nonprofit organisations in cause-related marketing: Stakeholder concerns and safeguarding strategies. European Journal of Marketing, 47(12), 1954-1974.

Litrico, J.-B., \& Besharov, M. L. (2019). Unpacking variation in hybrid organizational forms: Changing models of social enterprise among nonprofits, 2000-2013. Journal of Business Ethics, 159(2), 343-360.

Liu, G., Eng, T. Y., \& Takeda, S. (2015). An investigation of marketing capabilities in third sector: A study of British and Japanese social enterprise. Entrepreneurship Theory and Practice, 39(2), 267-298.

Liu, G., \& Ko, W. W. (2011). An analysis of cause-related marketing implementation strategies through social alliance: Partnership conditions and strategic objectives. Journal of Business Ethics, 100(2), 253-281.

Liu, G., \& Ko, W. W. (2012). Organizational learning and marketing capability development: A study of charity retailing operation of british social enterprises. Nonprofit and Voluntary Sector Quarterly, 41(4), 580-608.
Liu, G., \& Ko, W. W. (2014). Charity retailing in the UK: A managerial capabilities perspective. Journal of Small Business Management, $52(3), 390-406$.

Liu, G., Ko, W. W., \& Chapleo, C. (2018). How and when socially entrepreneurial nonprofit organizations benefit from adopting social alliance management routines to manage social alliances? Journal of Business Ethics, 151(2), 497-516.

Maguire, S., Hardy, C., \& Lawrence, T. B. (2004). Institutional entrepreneurship in emerging fields: HIV/Aids treatment advocacy in Canada. Academy of Management Journal, 47(5), 657-679.

Maier, F., Meyer, M., \& Steinbereithner, M. (2016). Nonprofit organizations becoming business-like: A systematic review. Nonprofit and Voluntary Sector Quarterly, 45(1), 64-86.

Munir, K. A., \& Phillips, N. (2005). The birth of the'kodak moment': Institutional entrepreneurship and the adoption of new technologies. Organization Studies, 26(11), 1665-1687.

Mutch, A. (2018). Practice, substance, and history: Reframing institutional logics. Academy of Management Review, 43(2), 242-258.

Nicholls, A. (2008). Social entrepreneurship: New models of sustainable social change. Oxford: Oxford University Press.

Nicholls, A. (2010). The legitimacy of social entrepreneurship: Reflexive isomorphism in a pre-paradigmatic field. Entrepreneurship Theory and Practice, 34(4), 611-633.

NVCO. (2012). The UK voluntary sector almanac 2012. London: National Council for Voluntary Organization.

Pache, A.-C., \& Santos, F. (2013). Inside the Hybrid organization: Selective coupling as a response to competing institutional logics. Academy of Management Journal, 56(4), 972-1001.

Palacios, M., Martinez-Corral, A., Nisar, A., \& Grijalvo, M. (2016). Crowdsourcing and Organizational forms: Emerging trends and research implications. Journal of Business Research, 69(5), 1834-1839.

Phillips, N., \& Tracey, P. (2007). Opportunity recognition, entrepreneurial capabilities and bricolage: Connecting institutional theory and entrepreneurship in strategic organization. Strategic Organization, 5(3), 313-320.

Powell, M., Gillett, A., \& Doherty, B. (2019). Sustainability in social enterprise: Hybrid Organizing in Public Services. Public Management Review, 21(2), 159-186.

Raman, A. (2016). How do social media, mobility, analytics and cloud computing impact nonprofit organizations? A pluralistic study of information and communication technologies in Indian context. Information Technology for Development, 22(3), $400-421$.

Ramus, T., \& Vaccaro, A. (2017). Stakeholders matter: How social enterprises address mission drift. Journal of Business Ethics, 143(2), 307-322.

Rao, H., Morrill, C., \& Zald, M. N. (2000). Power plays: How social movements and collective action create new organizational forms. Research in Organizational Behavior, 22, 237-281.

Rao, H., \& Singh, J. V. (2001). The Construction of New Paths: Institution Building Activity in the Early Automobile and Biotechnology Industries. In R. Garud \& P. Karnoe (Eds.), Path Dependence and Creation (pp. 243-267). Mahwah: Lawerence Erlbaum.

Roumpi, D., Magrizos, S., \& Nicolopoulou, K. (2019). Virtuous circle: Human capital and human resource management in social enterprises. Human Resource Management. https://doi.org/10.1002/ hrm.22002.

Sakarya, S., Bodur, M., Yildirim-Öktem, Ö., \& Selekler-Göksen, N. (2012). Social alliances: Business and social enterprise collaboration for social transformation. Journal of Business Research, 65(12), 1710-1720.

Sanders, M. L. (2015). Being nonprofit-like in a market economy: Understanding the mission-market tension in nonprofit organizing. Nonprofit and Voluntary Sector Quarterly, 44(2), 205-222. 
Sanders, M. L., \& McClellan, J. G. (2014). Being business-like while pursuing a social mission: Acknowledging the inherent tensions in us nonprofit organizing. Organization, 21(1), 68-89.

Saxton, G. D., \& Wang, L. (2014). The social network effect: The determinants of giving through social media. Nonprofit and Voluntary Sector Quarterly, 43(5), 850-868.

Staessens, M., Kerstens, P. J., Bruneel, J., \& Cherchye, L. (2019). Data envelopment analysis and social enterprises: Analysing performance, strategic orientation and mission drift. Journal of Business Ethics, 159(2), 325-341.

Strauss, A. L., \& Corbin, J. M. (2008). Basics of qualitative research: Techniques and procedures for developing grounded theory. Newbury Park, CA: Sage Publications.

Suarez, D. F. (2010). Street credentials and management backgrounds: Careers of nonprofit executives in an evolving sector. Nonprofit and Voluntary Sector Quarterly, 39(4), 696-716.

Teece, D. J. (2007). Explicating dynamic capabilities: The nature and microfoundations of (sustainable) enterprise performance. Strategic Management Journal, 28(13), 1319-1350.

Toepler, S. (2006). Caveat venditor? Museum merchandising, nonprofit commercialization, and the case of the metropolitan museum in New York. VOLUNTAS: International Journal of Voluntary and Nonprofit Organizations, 17(2), 99-113.

Tracey, P., Phillips, N., \& Jarvis, O. (2011). Bridging institutional entrepreneurship and the creation of new organizational forms: A multilevel model. Organization Science, 22(1), 60-80.

Treasury, H. M. (2002). The role of the voluntary and community sector in service delivery: A cross cutting review. London: HM Treasury.
Tung, W.-F., \& Jordann, G. (2017). Crowdsourcing social network service for social enterprise innovation. Information Systems Frontiers, 19(6), 1311-1327.

Tyler, B. B., \& Gnyawali, D. R. (2009). Managerial collective cognitions: An examination of similarities and differences of cultural orientations. Journal of Management Studies, 46(1), 93-126.

Vickers, I., Lyon, F., Sepulveda, L., \& McMullin, C. (2017). Public service innovation and multiple institutional logics: The case of hybrid social enterprise providers of health and wellbeing. Research Policy, 46(10), 1755-1768.

Weerawardena, J., \& Mort, G. (2012). Competitive strategy in socially entrepreneurial nonprofit organizations: Innovation and differentiation. Journal of Public Policy \& Marketing, 31(1), 91-101.

Wry, T., \& York, J. G. (2017). An identity-based approach to social enterprise. Academy of Management Review, 42(3), 437-460.

Yang, Y.-K., \& Wu, S.-L. (2016). In search of the right fusion recipe: The role of legitimacy in building a social enterprise model. Business Ethics: A European Review, 25(3), 327-343.

Zietsma, C., \& Lawrence, T. B. (2010). Institutional work in the transformation of an organizational field: The interplay of boundary work and practice work. Administrative Science Quarterly, 55(2), 189-221.

Publisher's Note Springer Nature remains neutral with regard to jurisdictional claims in published maps and institutional affiliations. 